\title{
Effects of olive oil and its minor phenolic constituents on obesity-induced cardiac metabolic changes
}

\author{
Geovana MX Ebaid ${ }^{1,2}$, Fábio RF Seiva ${ }^{1,2}$, Katiucha KHR Rocha', Gisele A Souza ${ }^{1,2}$, Ethel LB Novelli ${ }^{1 *}$
}

\begin{abstract}
Background: Olive oil and its minor constituents have been recommended as important dietary therapeutic interventions in preventive medicine. However, a question remains to be addressed: what are the effects of olive oil and its phenolic compounds on obesity-induced cardiac metabolic changes?

Methods: Male Wistar rats were divided into two groups ( $n=24 /$ group): (C) receiving standard-chow; $(\mathrm{Ob})$ receiving hypercaloric-chow. After 21 days $C$ and Ob groups were divided into four subgroups ( $n=6 /$ group):(C) standard-chow and saline; (C-Olive)standard-chow and olive-oil (3.0 g/kg.day); (C-Oleuropein)standard-chow and oleuropein ( $0.023 \mathrm{mg} / \mathrm{kg} /$ day); (C-Cafeic) standard-chow and cafeic-acid (2.66 mg/kg/day); (Ob)receiving hypercaloric-chow and saline;(Ob-Olive) hypercaloric-chow and olive-oil;(Ob-Oleuropein) hypercaloric-chow and oleuropein;(Ob-Cafeic) hypercaloric-chow and cafeic-acid. Treatments were given twice a week during 21 days.

Results: After 42 days, obesity was evidenced in Ob rats from enhanced body-weight, surface-area, and bodymass-index. Energy-expenditure, oxygen consumption $\left(\mathrm{VO}_{2}\right)$ and fat-oxidation were lower in Ob-group than in $\mathrm{C}$. Despite no morphometric changes, Ob-Olive, Ob-Oleuropein and Ob-Cafeic groups had higher $\mathrm{VO}_{2}$, fat-oxidation, myocardial beta-hydroxyacyl coenzyme-A dehydrogenase and lower respiratory-quotient than Ob. Citrate-synthase was highest in Ob-Olive group. Myocardial lipid-hydroperoxide(LH) and antioxidant enzymes were unaffected by olive-oil and its compounds in obesity condition, whereas LH was lower and total-antioxidant-substances were higher in C-Olive and C-Oleuropein than in C.
\end{abstract}

Conclusions: The present study demonstrated for the first time that olive-oil, oleuropein and cafeic-acid enhanced fat-oxidation and optimized cardiac energy metabolism in obesity conditions. Olive oil and its phenolic compounds improved myocardial oxidative stress in standard-fed conditions.

\section{Background}

Olive oil consumption was claimed as the basic food supply responsible for the low incidence of cardiovascular diseases in some societies [1]. Recent research has suggested that olive oil minor constituents might have more effects on health than once believed [1-5].

On this concern, a group of olive oil phenolic compounds, such as oleuropein and cafeic acid have attracted considerable attention because of their anti-diabetic [6,7], anti-atherosclerotic [8] and anti-inflammatory [9] properties. Olive oil minor components have been also

\footnotetext{
* Correspondence: drno@uol.com.br

'Department of Chemistry and Biochemistry, Institute of Biological Sciences, São Paulo State University, UNESP, 18618-000, Botucatu, São Paulo, Brazil Full list of author information is available at the end of the article
}

associated with the antioxidant activity of olive oil $[9,10]$, but little information is available on cardiac oxidative stress and energy metabolism in obesity conditions.

Cardiac muscle utilizes a variety of substrates to produce energy, and the heart can shift from one substrate to another depending on food intake and pathophysiological state [11]. There is a growing awareness that during energy metabolism, the mitochondrial respiratory chain represents a major intracellular source of reactive oxygen species (ROS). Alterations in food constituents or substrate for energy generation, as found in hypercaloric diet [12] may result in higher ROS, thus inducing oxidative stress, an imbalance between oxidants and antioxidants systems in favor of the former $[13,14]$. Recent research in our

\section{Biomed Central}


laboratory demonstrated that enhanced energy intake reduced the mitochondrial membrane fluidity, increasing ROS generation $[12,15]$.

Furthermore, it has been shown that blocking mitochondrial oxidative phosphorylation system increases lipid accumulation in adipocytes, and that in obesity there is decreased oxygen consumption, indicating impairment in mitochondrial activity [16]. Therefore, weight gain can be viewed not only as the consequence of an initial positive energy balance, but also as the mechanism by which energy balance is eventually stored. Whether obesity-related cardiac effects are due to an increase in caloric intake, a decrease in metabolic rate, or a combination of both factors is still unclear.

An excess of energy intake and/or a decrease in energy expenditure may reflect important metabolic dysfunction, for instance exacerbated fat storage and/or a deficit in oxidative metabolism [17]. However, it was not studied whether olive oil intake can alter calorimetric parameters and can improve energy metabolism in cardiac tissue of obese rats, which certainly would bring new insights on obesity-related cardiac metabolic changes control.

Thus, the aim of this study was to investigate the effects of olive oil and its minor phenolic constituents, oleuropein and cafeic acid, on calorimetric parameters, myocardial oxidative stress and energy metabolism in cardiac tissue of control and obese rats. Animal models are useful for increasing the understanding of the effects of diet and the development of obesity related abnormalities, particularly on cardiac tissue $[15,18]$. Therefore, we used a rat model to study the effects of olive oil and its phenolic compounds on an unresolved issue in the field of obesity and health that is the control of obesityrelated cardiac metabolic alterations.

\section{Methods}

\section{Obesity induction and experimental procedure}

All experiments and procedures were performed in accordance with the Guide for the Care and Use of Laboratory Animals published by the US National Institute of Health and were approved by the Ethics Committee of the Botucatu School of Medicine, UNESP, Botucatu, SP, Brazil. Forty eight male Wistar rats, 75 days of age, were individually housed in polypropylene cages in an environmentally controlled clean-air room with a temperature of $22 \pm 3^{\circ} \mathrm{C}$, a $12 \mathrm{~h}$ light-dark cycle and a relative humidity of $60 \pm 5 \%$. Taking into account the hormonal influences in female, we used only male rats.

Initially the animals were randomly divided into two groups ( $n=24 /$ group). The $(C)$ group received water ad libitum and standard rodent chow (3074 SIF, Purina Ltda., Campinas, SP, Brazil), containing (by weight) $19.80 \%$ protein, $39.25 \%$ carbohydrate, $4.41 \%$ fat, $13.25 \%$ fibre, and $2.76 \mathrm{kcal} / \mathrm{g}$ of metabolizable energy. The $(\mathrm{Ob})$ group received a hypercaloric chow containing $15.25 \%$ protein, $43.34 \%$ carbohydrate, $11.86 \%$ fat, $10.20 \%$ fibre (by weight) and $3.41 \mathrm{kcal} / \mathrm{g}$ of metabolizable energy.

The hypercaloric chow was made mixing $131.01 \mathrm{~g}$ sucrose, $84.77 \mathrm{~g}$ of soy oil, $12.33 \mathrm{~g}$ of cholesterol and $1.23 \mathrm{~g}$ cholic acid with $1000 \mathrm{~g}$ of a previously triturated standard chow. The dietary ingredients were homogenized in $60^{\circ} \mathrm{C}$ warm distilled water and the homogenate was used to prepare the pellets. Therefore, both control and hypercaloric diets were given as pellets, and there was no spillage. The proportions of dietary protein, carbohydrate and fat were determined by direct analysis [19]. Food and drinking solutions consumption were measured daily at the same time (9:00-10:00 h). The body weights were determined once a week.

In order to more appropriately study the effects of olive oil and its minor constituents on obesity, and standard fed conditions, after 21 days of dietary treatments, both $\mathrm{C}$ and $\mathrm{Ob}$ groups were then randomly divided into four subgroups ( $\mathrm{n}=6 /$ group): (C) remained to eat standard chow, receiving saline $(\mathrm{NaCl} 0,9 \%)$; (C-Olive) remained to eat standard chow, receiving olive oil supplementation $(3.0 \mathrm{~g} / \mathrm{kg} /$ day) $[20,21]$; (C-Oleuropein) remained to eat standard chow, receiving oleuropein $(0.023 \mathrm{mg} / \mathrm{kg} /$ day) [22]; (C-Cafeic) remained to eat standard chow, receiving cafeic acid $(2.66 \mathrm{mg} / \mathrm{kg} /$ day) [23]; $(\mathrm{Ob})$ remained to eat hypercaloric chow, receiving saline $(\mathrm{NaCl}$ 0,9\%); (Ob-Olive) remained to eat hypercaloric chow, receiving olive oil ( $3.0 \mathrm{~g} / \mathrm{kg} /$ day); (Ob-Oleuropein) remained to eat hypercaloric chow, receiving oleuropein $(0.023 \mathrm{mg} / \mathrm{kg} /$ day); (Ob-Cafeic) remained to eat hypercaloric chow, receiving cafeic acid $(2.66 \mathrm{mg} / \mathrm{kg} /$ day $)$. Treatments were given twice a week by gavage.

Extra-virgin olive oil was chosen for its high content of phenolic compounds and was purchased from the local market (Botucatu city, São Paulo State, Brazil). The olive oil administration was the adopted dose according to human olive oil consumption, and considered that the average consumption of olive oil in humans is $4 \%$ of the diet, twice a week [24]. This value corresponded to $1 \mathrm{~g}$ olive oil per $25 \mathrm{~g}$ of consumed chow, or $3 \mathrm{~g} / \mathrm{kg} /$ day olive oil for rats of C-Olive and Ob-Olive groups [21]. The olive oil was analysed for oleuropein [25] and cafeic acid [26]. The oleuropein and cafeic acid doses took into account that the amount of these compounds in the olive oil utilized was $7.78 \mathrm{mg} / \mathrm{l}$ oleuropein and 887.5 $\mathrm{mg} / \mathrm{l}$ cafeic acid. Since the amount of $3 \mathrm{~g} / \mathrm{kg} /$ day olive oil $[20,21]$ was given to the rats of control group, we administered $0.023 \mathrm{mg} / \mathrm{kg} /$ day oleuropein and $2.66 \mathrm{mg} /$ $\mathrm{kg} /$ day cafeic acid, twice a week. Oleuropein and cafeic acid were purchased from Sigma (St. Louis, MO, USA). Food intake and caloric value of chows were used to obtain total energy intake. 


\section{Indirect calorimetry}

After 21 days of dietary supplementations (42 days of the experimental period), the rats were fasted overnight (12 to $14 \mathrm{~h}$ ) and placed into metabolic chambers (airflow $=1.0 \mathrm{l} / \mathrm{min}$ ) of a computer-controlled indirect calorimeter (CWE, Inc, St. Paul, USA) to determine the calorimetric parameters. Respiratory quotient $(\mathrm{RQ})$ and energy expenditure, namely resting metabolic rate (RMR) were measured using a respiratory-based software program (software MMX, CWE, Inc., USA). Average oxygen consumption $\left(\mathrm{VO}_{2}\right)$ and average carbon dioxide production $\left(\mathrm{VCO}_{2}\right)$ were integrated over periods of $15 \mathrm{~min}$. Carbohydrate and fat oxidation were calculated from the no protein oxygen consumption and the amount of oxygen consumed per gram of substrate oxidized. The energy balance over $24 \mathrm{~h}$ was determined as energy intake minus energy expenditure [27].

\section{Morphometric and biochemical determinations}

After 42 days of experimental period, rats were fasted overnight (12 to $14 \mathrm{~h}$ ). The animals were anaesthetized ( $0.1 \mathrm{ml}$ ip of $1 \%$ sodium barbiturate) for measurement of body length (nose-to-anus, or nose-anal length) [19]. The body weight and body length were used to determine body mass index (BMI, body weight/body length ${ }^{2}$ ) and surface area (body weight ${ }^{0.7}$ ). After measuring the body length, the rats were sacrificed by decapitation. The heart was rapidly removed and weighed. The left ventricle samples of $200 \mathrm{mg}$ were homogenized in $5 \mathrm{~mL}$ of a cold 0.1 M phosphate buffer, pH7.4. Tissue homogenates were prepared in a motor-driven Teflon-glass Potter-Elvehjem, tissue homogeniser $(1 \mathrm{~min}, 100 \times g)$. The homogenate was centrifuged at $10000 \times g$, for 15 min, and the supernatant was assayed for total protein [28], lipid hydroperoxide (LH) [29], antioxidant capacity, or total antioxidant substances (TAS) (test-kit Randox Laboratories, Crumlin, Co., Antrim, United Kingdom), glutathione peroxidase (GSH-Px, E.C.1.11.1.9) [30], catalase (E.C.1.11.1.6.) [31] and superoxide dismutase (SOD, E.C.1.15.1.1.) [32].

Several key metabolic enzymes were studied to reveal the possible alteration of myocardial function due obesity. The cardiac energy metabolism was assessed by lactate dehydrogenase (LDH; E.C.1.1.127.), beta-hydroxyacyl coenzyme-A dehydrogenase (OHADH; E. C.1.1.1.35.) and citrate synthase (CS; E.C.4.1.3.7.) determinations [33].

Enzyme activities were performed at $25^{\circ} \mathrm{C}$ using a micro-plate reader ( $\mu$ Quant-MQX 200 with Kcjunior software to computer system control, Bio-Tec instruments, Winooski, Vermont, USA). The spectrophotometric determinations were performed in a Pharmacia Biotech spectrophotometer with temperature-controlled cuvette chamber (UV/visible Ultrospec 5,000 with Swift
II applications software to computer system control, 974213, Cambridge, England, UK).

\section{Statistical analysis}

The results are presented as means \pm standard deviations (S.D). Analysis of variance for two variables (Two Way-ANOVA) was used to examine the diet and supplementation treatment effects. Significant analysis of variance results were subjected to post hoc Tukey's test. Statistical significance was set at $p<0.05$ (Systat Software, USA).

\section{Results}

General characteristics of rats, nutritional and calorimetric parameters

Hypercaloric diet significantly increased final body weight, BMI and surface area. Despite no changes in food consumption, the energy intake was higher in $\mathrm{Ob}$ than in $\mathrm{C}$ rats. $\mathrm{Ob}$ rats had depressed $\mathrm{VO}_{2}, \mathrm{VO}_{2}$ /body weight, $\mathrm{VO}_{2}$ /surface area, RMR, RMR/body weight and fat oxidation, as well enhanced $R Q, R Q /$ surface area, carbohydrate oxidation and energy balance, comparing with $C$ rats (Table 1). Olive oil, oleuropein and cafeic acid in control-fed and obese-rats had no effects on final body weight, surface area, BMI, food consumption and energy intake.

Table 1 General characteristics and calorimetric parameters of rats after 42 days of standard fed (C), and hypercaloric fed (Ob) diets

\begin{tabular}{|c|c|c|}
\hline \multirow[b]{2}{*}{ Parameters } & \multicolumn{2}{|c|}{ Groups } \\
\hline & $\mathrm{C}$ & $\mathrm{Ob}$ \\
\hline Final body weight (g) & $335.75 \pm 54.32$ & $397.66 \pm 36.54^{a}$ \\
\hline Surface area $\left(g^{0.7}\right)$ & $58.51 \pm 6.60$ & $65.96 \pm 4.29^{\mathrm{a}}$ \\
\hline BMI $\left(\mathrm{g} / \mathrm{cm}^{2}\right)$ & $0.54 \pm 0.03$ & $0.65 \pm 0.05^{\mathrm{a}}$ \\
\hline Food consumption (g/day) & $25.4 \pm 4.6$ & $25.3 \pm 1.4$ \\
\hline Energy intake (kcal/day) & $70.07 \pm 4.30$ & $86.27 \pm 4.09^{a}$ \\
\hline $\mathrm{VO}_{2}(\mathrm{ml} / \mathrm{min})$ & $3.80 \pm 0.06$ & $3.46 \pm 0.11^{a}$ \\
\hline $\mathrm{VCO}_{2}(\mathrm{ml} / \mathrm{min})$ & $2.35 \pm 0.001$ & $2.49 \pm 0.002^{\mathrm{a}}$ \\
\hline $\mathrm{RQ}$ & $0.63 \pm 0.04$ & $0.84 \pm 0.03^{\mathrm{a}}$ \\
\hline RMR (kcal/h) & $1.07 \pm 0.02$ & $0.97 \pm 0.01^{\mathrm{a}}$ \\
\hline $\mathrm{VO}_{2} /$ body weight (ml/h.kg) & $11.58 \pm 1.78$ & $8.75 \pm 0.53^{\mathrm{a}}$ \\
\hline $\mathrm{VO}_{2} /$ surface area $\left(\mathrm{mL} / \mathrm{h} \cdot \mathrm{g}^{0.7}\right)$ & $3.94 \pm 0.42$ & $3.15 \pm 0.12^{\mathrm{a}}$ \\
\hline $\mathrm{RQ} /$ body weight & $0.19 \pm 0.03$ & $0.21 \pm 0.02$ \\
\hline $\mathrm{RQ} /$ surface area & $1.10 \pm 0.02$ & $1.28 \pm 0.10^{\mathrm{a}}$ \\
\hline RMR/body weight (kcal/h.kg) & $3.25 \pm 0.04$ & $2.46 \pm 0.23^{\mathrm{a}}$ \\
\hline Fat oxidation (mg/min) & $3.50 \pm 0.39$ & $1.38 \pm 0.28^{\mathrm{a}}$ \\
\hline Carbohydrate oxidation (mg/min) & - & $1.19 \pm 0.25^{\mathrm{a}}$ \\
\hline Energy balance (kcal/day) & $49.65 \pm 5.51$ & $62.93 \pm 4.27 a$ \\
\hline
\end{tabular}

Values are given as mean \pm SD.

$\mathrm{C}$, control rats; $\mathrm{Ob}$, obese rats; $\mathrm{BMI}$, body mass index; $\mathrm{VO}_{2}$ oxygen consumption; $\mathrm{VCO}_{2}$ dioxide carbon production; $\mathrm{RQ}$, respiratory quotient; $\mathrm{RMR}$, resting metabolic rate.

${ }^{a} p<0.05$ vs. C group. 
C-Olive and C-Cafeic rats had higher $\mathrm{VO}_{2}, \mathrm{VCO}_{2}$, RMR and fat oxidation than $\mathrm{C} . \mathrm{VO}_{2}$ /surface area, $\mathrm{RQ}$ and $\mathrm{RQ} /$ surface area were higher in C-Olive than in C. $\mathrm{C}$-Oleuropein rats had lower $\mathrm{VO}_{2}, \mathrm{RMR}$ and fat oxidation, as well higher $R Q$ and $R Q /$ surface area than C-Olive. C-Cafeic rats had higher $\mathrm{VO}_{2}, \mathrm{RMR}$ and fat oxidation, as well lower RQ, RQ/body weight and RQ/ surface area than C-Oleuropein (Table 2). Ob-Olive, Oboleuropein and Ob-Cafeic rats had lower RQ, RQ/body weight and $\mathrm{RQ} /$ surface area, as well higher fat oxidation than $\mathrm{Ob}$. The $\mathrm{VO}_{2}$ and energy balance were higher, while RMR and RMR/body weight were lower in Ob-Cafeic than in Ob, Ob-Olive and Ob-Oleuropein rats (Table 3). The carbohydrate oxidation was not detected in $\mathrm{C}$, C-Olive and C-Cafeic, as well in Ob-Olive, Ob-Oleuropein and Ob-Cafeic rats (Tables 2 and 3).

\section{Morphometric and biochemical determinations in the heart}

The heart weight, heart weight/body weight ratio, total protein, catalase, GSH-Px and LDH were unaffected by the treatments in both dietary conditions (Tables 4 and 5).

Myocardial LH was lower, and TAS was higher in $\mathrm{C}$-Olive and C-Oleuropein than in C. SOD was lower in C-Cafeic than in $\mathrm{C}$ and C-Oleuropein groups (Table 4). Myocardial LH and TAS remained unchanged in hypercaloric fed animals (Table 5).

$\mathrm{C}$-cafeic rats had the lowest OHADH activity. Ob-Olive, Ob-Oleuropein and Ob-Cafeic rats had higher $\mathrm{OHADH}$ than $\mathrm{Ob}$ (Figure 1). CS was lower in
C-Oleuropein than in $\mathrm{C}$, as well in Ob-Olive than in $\mathrm{Ob}$ group (Figure 2).

\section{Discussion}

Dietary olive oil supplementation [20], and more recently olive oil phenols [21] have been recommended as important therapeutic interventions in preventive medicine. However, a question remains to be addressed: what are the effects of olive oil and its minor phenolic compounds on obesity-induced cardiac metabolic changes?

To the best of our knowledge this is the first study that evaluated the relative potency of olive oil and its phenolic constituents, oleuropein and cafeic acid, on some markers of metabolic pathways in cardiac tissue of obese rats, as well their relationships with calorimetric parameters and oxidative stress. The present study brought new insights into the long term and low-dose intake of olive oil and its compounds on cardiac energy metabolism.

To demonstrate the efficiency of obesity induction $[19,34]$ despite the same food intake, Ob rats showed higher final body weight, surface area and BMI than C (Table 1). Prospective studies [35] demonstrated that a relatively low RMR and a high RQ [36] are predictors of body weight gain. In fact, as previously observed [34] obesity was characterized in $\mathrm{Ob}$ rats from reduced $\mathrm{RMR}$, oxygen consumption, $\mathrm{VO}_{2}$ / final body weight and $\mathrm{VO}_{2}$ /surface area, corroborating with lower fat oxidation (Table 1). There was also higher energy balance indicating that energy intake exceeded energy expenditure for

Table 2 Calorimetric parameters of standard-fed rats

\begin{tabular}{|c|c|c|c|c|}
\hline \multirow[b]{2}{*}{ Calorimetric parameters } & \multicolumn{4}{|c|}{ Groups } \\
\hline & C & C-Olive & C-Oleuropein & C-Cafeic \\
\hline $\mathrm{VO}_{2}(\mathrm{ml} / \mathrm{min})$ & $3.80 \pm 0.06$ & $4.77 \pm 0.37^{a}$ & $3.44 \pm 0.09^{b}$ & $4.45 \pm 0.26^{\mathrm{ac}}$ \\
\hline $\mathrm{VCO}_{2}(\mathrm{ml} / \mathrm{min})$ & $2.35 \pm 0.001$ & $2.36 \pm 0.002^{a}$ & $2.37 \pm 0.002^{\mathrm{ab}}$ & $2.38 \pm 0.002^{a b c}$ \\
\hline $\mathrm{RQ}$ & $0.63 \pm 0.04$ & $0.54 \pm 0.04^{\mathrm{a}}$ & $0.78 \pm 0.03^{b}$ & $0.60 \pm 0.03^{c}$ \\
\hline RMR (kcal/h) & $1.07 \pm 0.02$ & $1.21 \pm 0.09^{a}$ & $0.97 \pm 0.04^{\mathrm{ab}}$ & $1.18 \pm 0.06^{\mathrm{ac}}$ \\
\hline $\mathrm{VO}_{2}$ /body weight (ml/h.kg) & $11.58 \pm 1.78$ & $13.46 \pm 1.45$ & $10.13 \pm 1.21^{b}$ & $12.02 \pm 1.17$ \\
\hline $\mathrm{VO}_{2}$ /surface area (mL/h.g ${ }^{0.7}$ ) & $3.94 \pm 0.42$ & $4.69 \pm 0.38^{a}$ & $3.49 \pm 0.31^{\mathrm{a}}$ & $4.25 \pm 0.33^{b}$ \\
\hline $\mathrm{RQ} /$ body weight & $0.19 \pm 0.03$ & $0.15 \pm 0.02^{a}$ & $0.23 \pm 0.02^{b}$ & $0.16 \pm 0.01^{c}$ \\
\hline $\mathrm{RQ} /$ surface area & $1.10 \pm 0.02$ & $0.88 \pm 0.08^{a}$ & $1.31 \pm 0.1^{\mathrm{ab}}$ & $0.95 \pm 0.07^{c}$ \\
\hline RMR/body weight (kcal/h.kg) & $3.25 \pm 0.04$ & $3.44 \pm 0.55$ & $2.85 \pm 0.36$ & $3.19 \pm 0.30$ \\
\hline Fat oxidation (mg/min) & $3.50 \pm 0.39$ & $5.55 \pm 0.49^{\mathrm{a}}$ & $1.92 \pm 0.35^{\mathrm{ab}}$ & $4.55 \pm 0.64^{\mathrm{abc}}$ \\
\hline Carbohydrate oxidation (mg/min) & Not detected & Not detected & $0.64 \pm 0.33$ & Not detected \\
\hline Energy Balance (kcal/day) & $49.65 \pm 5.51$ & $50.90 \pm 8.86$ & $52.49 \pm 7.37$ & $54.66 \pm 9.92$ \\
\hline
\end{tabular}

Values are given as mean $\pm \mathrm{SD}$.

C, control rats receiving saline; C-Olive, standard-fed rats receiving olive oil; C-Oleuropein, standard-fed rats receiving oleuropein; C-Cafeic, standard-fed rats receiving cafeic acid; $\mathrm{VO}_{2}$ oxygen consumption; $\mathrm{VCO}_{2}$, dioxide carbon production; $\mathrm{RQ}$, respiratory quotient; $\mathrm{RMR}$, resting metabolic rate.

${ }^{a} p<0.05$ vs. $C$ group.

${ }^{\mathrm{b}} p<0.05$ vs. C-Olive group.

c $p<0.05$ vs. C-Oleuropein group. 
Table 3 Calorimetric parameters of obese rats

\begin{tabular}{|c|c|c|c|c|}
\hline \multirow[b]{2}{*}{ Calorimetric parameters } & \multicolumn{4}{|c|}{ Groups } \\
\hline & $\mathrm{Ob}$ & Ob-Olive & Ob-Oleuropein & Ob-Cafeic \\
\hline $\mathrm{VO}_{2}(\mathrm{ml} / \mathrm{min})$ & $3.46 \pm 0.11$ & $3.60 \pm 0.27$ & $3.78 \pm 0.23$ & $4.00 \pm 0.14^{\mathrm{ab}}$ \\
\hline $\mathrm{VCO}_{2}(\mathrm{ml} / \mathrm{min})$ & $2.49 \pm 0.002$ & $2.47 \pm 0.002^{\mathrm{a}}$ & $2.47 \pm 0.014^{\mathrm{a}}$ & $2.48 \pm 0.005^{c}$ \\
\hline $\mathrm{RQ}$ & $0.84 \pm 0.03$ & $0.64 \pm 0.03^{a}$ & $0.70 \pm 0.11^{a}$ & $0.66 \pm 0.03^{a}$ \\
\hline RMR (kcal/h) & $0.97 \pm 0.01$ & $0.97 \pm 0.04$ & $1.05 \pm 0.06$ & $0.42 \pm 0.07^{\mathrm{abc}}$ \\
\hline $\mathrm{VO}_{2} /$ body weight $(\mathrm{ml} / \mathrm{h} \cdot \mathrm{kg})$ & $8.75 \pm 0.53$ & $9.39 \pm 1.35$ & $9.49 \pm 0.88$ & $10.12 \pm 0.93$ \\
\hline $\mathrm{VO}_{2} /$ surface area $\left(\mathrm{ml} / \mathrm{h} \cdot \mathrm{g}^{0.7}\right)$ & $3.15 \pm 0.12$ & $3.35 \pm 0.42$ & $3.43 \pm 0.29$ & $3.64 \pm 0.27$ \\
\hline $\mathrm{RQ} /$ body weight & $0.21 \pm 0.02$ & $0.16 \pm 0.01^{\mathrm{a}}$ & $0.17 \pm 0.02^{\mathrm{a}}$ & $0.17 \pm 0.01^{\mathrm{a}}$ \\
\hline $\mathrm{RQ} /$ surface area & $1.28 \pm 0.10$ & $0.99 \pm 0.08^{\mathrm{a}}$ & $1.06 \pm 0.16^{\mathrm{a}}$ & $1.00 \pm 0.07^{\mathrm{a}}$ \\
\hline RMR/body weight (kcal/h.kg) & $2.46 \pm 0.23$ & $2.54 \pm 0.34$ & $2.63 \pm 0.27$ & $1.06 \pm 0.23^{\mathrm{abc}}$ \\
\hline Fat oxidation (mg/min) & $1.38 \pm 0.28$ & $3.31 \pm 0.57^{a}$ & $2.85 \pm 1.26^{\mathrm{a}}$ & $3.42 \pm 0.42^{a}$ \\
\hline Carbohydrate oxidation (mg/min) & $1.19 \pm 0.25$ & Not detected & Not detected & Not detected \\
\hline Energy Balance (kcal/day) & $62.93 \pm 4.27$ & $62.42 \pm 4.60$ & $63.11 \pm 4.57$ & $76.55 \pm 5.05^{\mathrm{abc}}$ \\
\hline
\end{tabular}

Values are given as mean \pm SD.

Ob, Obese rats receiving saline; Ob-Olive, obese rats receiving olive oil; Ob-Oleuropein, obese rats receiving oleuropein; Ob-cafeic, obese rats receiving cafeic acid; $\mathrm{VO}_{2}$, oxygen consumption; $\mathrm{VCO}_{2}$, dioxide carbon production; $\mathrm{RQ}$, respiratory quotient; $\mathrm{RMR}$, resting metabolic rate.

${ }^{a} p<0.05$ vs. Ob group.

${ }^{\mathrm{b}} p<0.05$ vs. Ob-Olive group.

${ }^{c} p<0.05$ vs. Ob-Oleuropein group.

vital functions (RMR), thus providing greater amount of energy to be stored as fat.

The detected fasting carbohydrate oxidation in $\mathrm{Ob}$ group was associated with liver glycogen storage due hypercaloric diet intake in these animals. Since the influence of the meal had essentially ended in the post absorptive state, the fasting RQ value gives an indication of the glycogen storage [27].

As previously found $[20,21]$, in both dietary conditions there were no significant alterations in morphometric parameters by olive oil and its phenolic compounds. There were no significant changes in heart weight, heart weight/body weight, as well as in cardiac protein, indicating adequate protein supply in both dietary conditions.

The lower RMR in C-Oleuropein rats, as well the higher RMR in C-Olive and C-Cafeic rats were not enough to significantly change the energy available for fat storage (Table 2). Note that in C-Olive and C-Cafeic rats there was a better fat utilization and this was evidenced by the lower RQ [34] in these animals. The detected carbohydrate oxidation in C-Oleuropein rats was associated with the highest $R Q, R Q /$ body weight and $\mathrm{RQ} /$ surface area found in these animals (Table 2).

Table 4 Morphometric and biochemical determinations in the heart of standard fed rats

\begin{tabular}{|c|c|c|c|c|}
\hline \multirow[b]{2}{*}{ Cardiac determinations } & \multicolumn{4}{|c|}{ Groups } \\
\hline & C & C-Olive & C-Oleuropein & C-Cafeic \\
\hline Heart weight (g) & $0.95 \pm 0.14$ & $1.03 \pm 0.10$ & $1.00 \pm 0.11$ & $1.05 \pm 0.05$ \\
\hline Heart weight/body weight (g/kg) & $2.85 \pm 0.17$ & $2.88 \pm 0.08$ & $2.90 \pm 0.05$ & $2.84 \pm 0.21$ \\
\hline Total protein (g/g tissue) & $0.18 \pm 0.03$ & $0.17 \pm 0.01$ & $0.17 \pm 0.02$ & $0.19 \pm 0.01$ \\
\hline $\mathrm{LH}$ (nmol/g tissue) & $150.07 \pm 9.96$ & $135.03 \pm 3.18^{a}$ & $129.93 \pm 6.66^{a}$ & $144.20 \pm 14.75$ \\
\hline TAS $(\%)$ & $26.78 \pm 2.39$ & $31.40 \pm 2.04^{a}$ & $33.51 \pm 3.39^{a}$ & $27.96 \pm 6.48$ \\
\hline LH/TAS & $5.81 \pm 1.56$ & $4.40 \pm 1.04$ & $3.92 \pm 0.55^{a}$ & $5.60 \pm 2.38$ \\
\hline SOD ( $\mu \mathrm{mol} / \mathrm{g}$ protein) & $9.90 \pm 0.73$ & $8.77 \pm 0.82$ & $9.32 \pm 0.97$ & $7.6 \pm 0.63^{\mathrm{ac}}$ \\
\hline Catalase (nmol/g protein) & $985.0 \pm 80.7$ & $967.4 \pm 49.7$ & $956.5 \pm 101.6$ & $887.0 \pm 90.3$ \\
\hline GSH-Px (nmol/mg protein & $6.65 \pm 4.95$ & $6.31 \pm 3.14$ & $6.93 \pm 1.31$ & $5.58 \pm 1.93$ \\
\hline LDH (nmol/mg protein) & $751.5 \pm 116.8$ & $781.6 \pm 75.7$ & $712.8 \pm 235.3$ & $636.6 \pm 108.5$ \\
\hline
\end{tabular}

Values are given as mean \pm SD.

$\mathrm{C}$, control rats receiving saline; C-Olive, standard-fed rats receiving olive oil; C-Oleuropein, standard-fed rats receiving oleuropein; C-Cafeic, standard-fed rats receiving cafeic acid; $\mathrm{LH}$, lipid hydroperoxide; TAS, total antioxidant substances; SOD, superoxide dismutase; GSH-Px, glutathione peroxidase; LDH, lactate dehydrogenase.

${ }^{a} p<0.05$ vs. $C$ group.

${ }^{\mathrm{b}} p<0.05$ vs. C-Olive group.

c $p<0.05$ vs. C-Oleuropein group. 
Table 5 Morphometric and biochemical determinations in the heart of obese rats

\begin{tabular}{lcccc}
\hline & \multicolumn{3}{c}{ Groups } \\
\cline { 2 - 5 } Cardiac determinations & Ob & Ob-Olive & Ob-Oleuropein & Ob-Cafeic \\
\hline Heart weight $(\mathrm{g})$ & $1.05 \pm 0.08$ & $1.01 \pm 0.08$ & $1.04 \pm 0.08$ & $1.04 \pm 0.09$ \\
Heart weight/body weight $(\mathrm{g} / \mathrm{kg})$ & $2.67 \pm 0.23$ & $2.62 \pm 0.24$ & $2.61 \pm 0.08$ & $2.62 \pm 0.09$ \\
Total protein (g/g tissue) & $0.16 \pm 0.02$ & $0.17 \pm 0.01$ & $0.17 \pm 0.01$ & $0.18 \pm 0.03$ \\
LH (nmol/g tissue) & $127.89 \pm 7.57$ & $135.00 \pm 2.28$ & $127.95 \pm 9.32$ & $126.83 \pm 8.69$ \\
TAS (\%) & $30.89 \pm 3.55$ & $30.12 \pm 1.44$ & $30.24 \pm 3.54$ & $31.02 \pm 3.54$ \\
LH/TAS & $4.19 \pm 0.63$ & $4.49 \pm 0.26$ & $4.30 \pm 0.75$ & $4.15 \pm 0.68$ \\
SOD ( $\mu$ mol/g protein) & $9.56 \pm 0.92$ & $8.95 \pm 1.14$ & $9.78 \pm 0.31$ & $9.06 \pm 1.36$ \\
Catalase (nmol/g protein) & $973.1 \pm 126.1$ & $1084.3 \pm 99.5$ & $1039.0 \pm 75.1$ & $1064.3 \pm 235.3$ \\
GSH-Px (nmol/mg protein & $5.90 \pm 2.44$ & $5.37 \pm 1.50$ & $6.55 \pm 1.26$ & $5.80 \pm 0.54$ \\
LDH (nmol/mg protein) & $780.0 \pm 83.4$ & $878.9 \pm 137.8$ & $758.6 \pm 96.8$ & $792.2 \pm 71.8$ \\
\hline
\end{tabular}

Values are given as mean $\pm \mathrm{SD}$.

Ob, Obese rats receiving saline; Ob-Olive, obese rats receiving olive oil; Ob-Oleuropein, obese rats receiving oleuropein; Ob-cafeic, obese rats receiving cafeic acid; LH, lipid hydroperoxide; TAS, total antioxidant substances; SOD, superoxide dismutase; GSH-Px, glutathione peroxidase; LDH, lactate dehydrogenase.

${ }^{a} p<0.05$ vs. Ob group.

${ }^{\mathrm{b}} p<0.05$ vs. Ob-Olive group.

${ }^{c} p<0.05$ vs. Ob-Oleuropein group.

Therefore, the lower fat oxidation in C-Oleuropein animals was not surprising, since the change in fuel selection is controlled by carbohydrate intake, and when carbohydrate oxidation rises in response to intake, there is a profound counterregulatory suppression of fat oxidation, because triacylglycerol lipase enzyme from the adipose tissue is inhibited by the insulin secretion [11]. Oleuropein enhanced glucose uptake in tissues, increasing insulin response [6] and the glycogen storage [36].

It was widely accepted that oxygen consumed for carbon dioxide liberation, during substrate oxidation depends upon the oxygen amount in dietary nutrient. Because fat oxidation requires more oxygen, there was a significant reduction in the $R Q, R Q /$ body weight and $\mathrm{RQ}$ /surface area in Ob-Olive, Ob-Oleuropein and ObCafeic rats (Table 3).

Several mechanisms may be associated with increased fat oxidation in obese rats receiving olive oil and its phenolic components. It is well known that absorption and delivery of dietary compounds by intestinal cells are part of a complex process, which is influenced by the physiological state of enterocytes. A persistent situation of redox imbalance, due to hypercaloric diet intake has been associated with gastrointestinal alterations [37]. Under these conditions, it might be expected an imbalance in the absorption of dietary compounds and the metabolic utilization for energy generation [38]. Olive oil and its compounds modulating cellular signal [39] and the activity of peptidases $[3,40]$ would allow the adequate balance between uptake and metabolism of dietary compounds.

Judging from our experimental results, it was evident that the beneficial effects of olive oil and its minor constituents enhancing fat oxidation were reflected in cardiac tissue of obese rats. Note that there was no antioxidant activity of olive oil and its phenolic compounds in cardiac tissue of animals fed with hypercaloric diet.

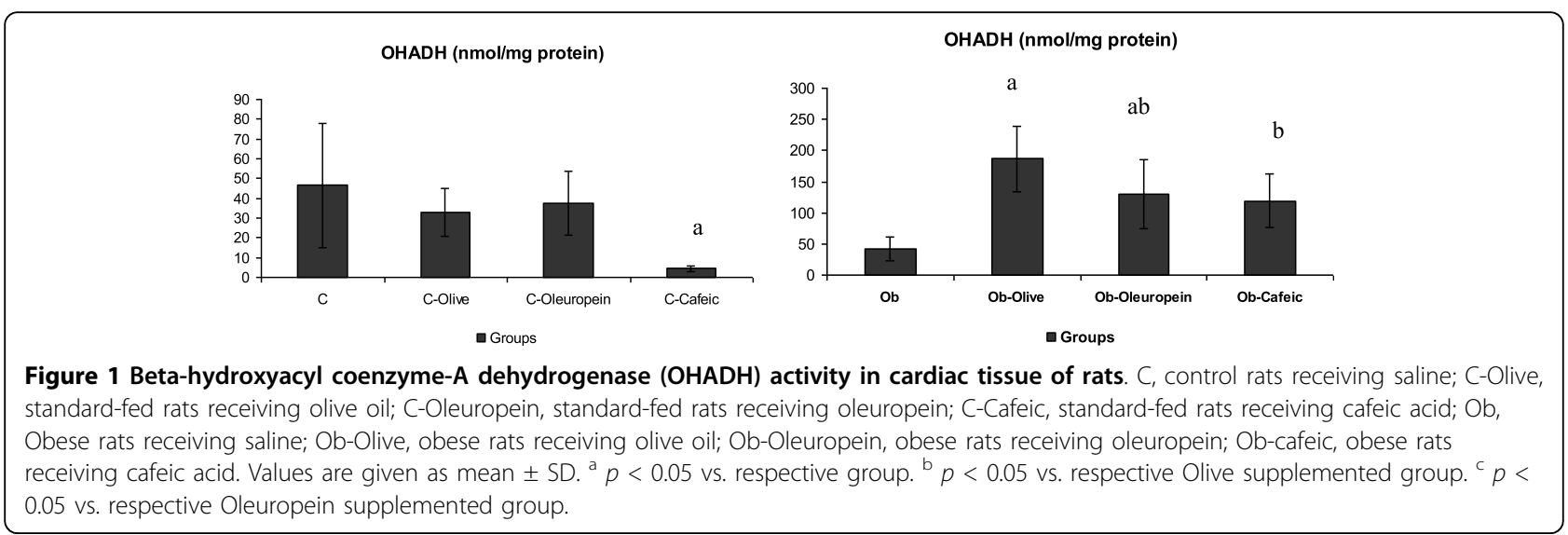




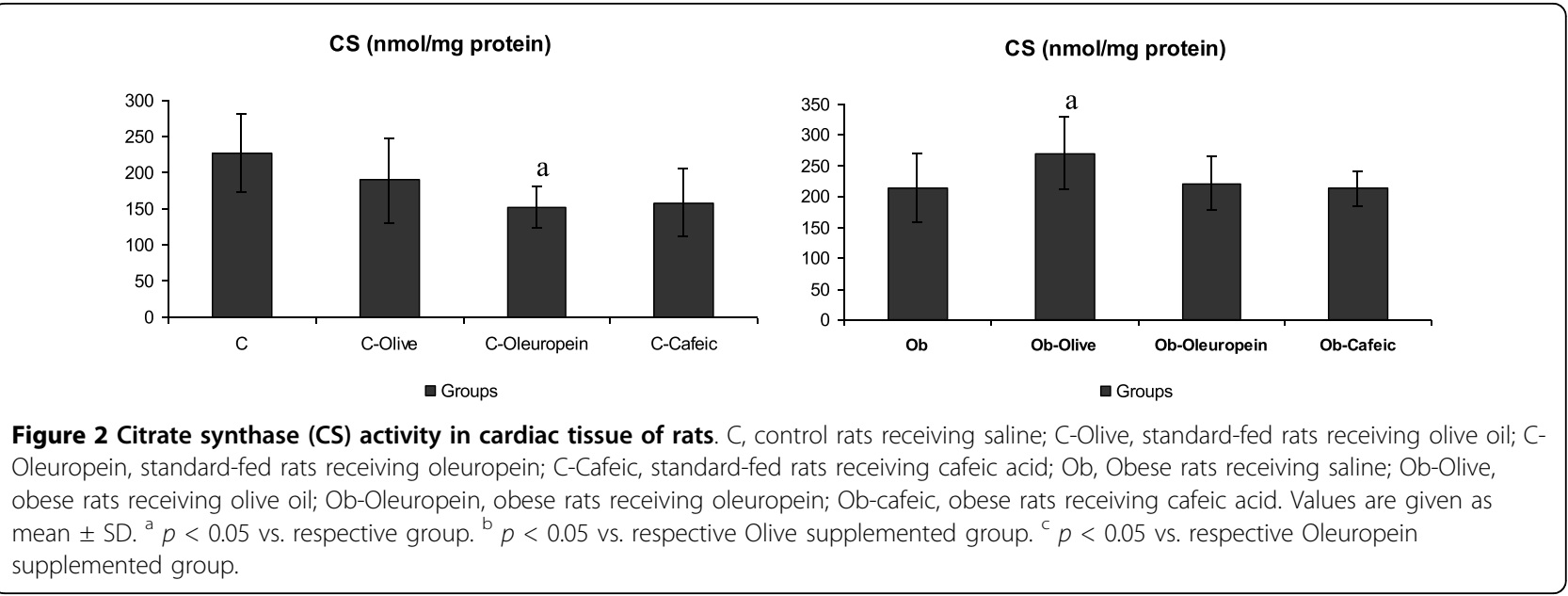

The enhanced fat oxidation was demonstrated in cardiac tissue by higher OHADH and CS activities in ObOlive rats (Figure 1 and 2). OHADH is a key enzyme for fatty acid oxidation, and CS is the key enzyme for the control of the flux of metabolites through tricarboxylic acid cycle. A clear link between triacylglycerol accumulation and the cardiomyopathy was established in experimental models in which the rate of fatty acid uptake by the heart was increased, or the capacity for fatty acid oxidation was reduced in the mitochondria [41]. Myocardial OHADH activity was also significantly enhanced by oleuropein and cafeic acid in obese animals, despite the maintenance of CS activity in these animals. It has been shown that hypercaloric diet induces adverse effects on cardiac function through changes in fatty acid metabolism, by inappropriate activation and expression of PPAR $\alpha$ (peroxisome-proliferator-activated receptor $\alpha$ ) as a result of glucotoxicity. The decrease in the transcription of PPAR $\alpha$ may be a regulatory event for the reduced use of fatty acids [42]. Thus, cafeic acid and oleuropein could allow adequate PPAR $\alpha$ activation and fatty acid utilization, increasing the OHADH activity under obesity conditions, reducing triacylglycerol accumulation in cardiac muscle. Optimizing cardiac energy metabolism in obese conditions may be one approach to prevent and treat cardiac dysfunction $[11,13]$.

Curiously, no significant changes were found in myocardial metabolic enzymes of C-Olive rats, whereas, CS was significantly reduced in $\mathrm{C}$-Oleuropein rats, despite no changes in OHADH (Figure 1 and 2). This indicated enhanced glycolytic pathway relative to aerobic metabolism, or delayed flux of metabolites through tricarboxylic acid cycle in cardiac tissue. Glycolysis preferentially serves energy channeling to sarcolemmal membranes, were glucose transport into cells occurs, by providing this readily available substrate for glycolytic enzymes bound to sarcolemmal molecular complexes [13]. Glycolytic pathway thus represents low capacity, but high specificity modules of the integrated metabolic network of a cardiac myocite [11]. On the other hand, the reduced $\mathrm{OHADH}$, and the maintenance of CS activity, clearly indicated that $\mathrm{C}$-Cafeic rats had depressed fatty acid degradation, relative to aerobic metabolism in cardiac tissue, as compared to $\mathrm{C}$, C-Olive and C-Oleuropein rats. Therefore, in standard fed conditions, dietary supplementation with olive oil phenolic compounds induced changes in the substrate used for energy generation in cardiac tissue. Further studies may be considered to clear this open question, and to show the importance of these changes on cardiac function.

Anyhow, the beneficial effect of olive oil in standardfed condition was evidenced from the reduced myocardial LH in these animals (Table 4). Lipids accumulation within the myocardium induces cardiac lipotoxicity $[12,13]$. Oxidative stress and lipotoxicity with increased LH may affect myocardial function, in a fashion that mimics reperfusion injury including persistent cellular loss of $\mathrm{K}^{+}$, depletion of energy phosphates and decreased metabolic function [43]. Note that despite the effects of cafeic acid reducing myocardial SOD, no significant changes were found in LH and TAS concentrations as compared with $C$ rats.

Although both oleuropein and olive oil have reduced $\mathrm{LH}$, the antioxidant responses in both groups occurred by different ways. The antioxidant defense system includes SOD that catalyzes the destruction of superoxide radical $\left(\mathrm{O}_{2}^{-}\right)$by dismutation and hydrogen peroxide formation, catalase and GSH-peroxidase that catalyzes the conversion of hydrogen peroxide to water. The total antioxidant substances (TAS) include non-enzymatic, lipophilic and aqueous antioxidants [11]. Enhanced TAS was associated with direct antioxidant activity of olive oil and oleuropein, because of the free radical scavenger 
ability [44]. This property depends on the number of hydroxyl radicals in the phenolic molecule [21]. Oleuropein and hydroxytyrosol, free radical scavengers, have antioxidant activity as found in other antioxidants, such as vitamin E and butylated hydroxytoluene (BHT) [20]. On the other hand, it has been demonstrated that olive oil may interfere in iron absorption [24]. Considering the importance of iron in the oxidative stress induction, the reduced iron uptake and diminished serum concentration of iron may be alternative mechanism for reduced myocardial LH in C-Olive animals.

\section{Conclusions}

In conclusion, the present study brought new insights of olive oil effects on obesity related cardiac metabolic changes, demonstrating for the first time that olive oil enhanced fat oxidation and regulated myocardial metabolic enzymes, optimizing cardiac energy metabolism in obesity conditions. Olive oil and its minor phenolic compounds, oleuropein and cafeic acid had myocardial antioxidant activity in standard-fed conditions.

\section{Acknowledgements}

The authors inform that there are no conflicts of interest. The authors thank the financial support from FAPESP, Fundação de Amparo a Pesquisa do Estado de São Paulo and CNPq, Conselho Nacional de Desenvolvimento Científico e Tecnológico.

\section{Author details}

'Department of Chemistry and Biochemistry, Institute of Biological Sciences, São Paulo State University, UNESP, 18618-000, Botucatu, São Paulo, Brazil. ${ }^{2}$ Post Graduation Course Department of Clinical and Cardiology, School of Medicine, São Paulo State University, UNESP, Botucatu, São Paulo, Brazil.

\section{Authors' contributions}

GMXE took part in planning the study design, sample analysis, analyzed the data and involved in drafting and writing of manuscript. FRFS contributed to the study design, sample analysis and performed the statistical analysis. KKHRR and GSA involved in drafting and sample analysis. ELBN took part in planning and supervising the study design, contributed to the analysis, writing of manuscript, edited the paper, revising it critically for important intellectual content and provided the final version. All authors read and approved the final manuscript.

\section{Competing interests}

The authors declare that they have no competing interests.

Received: 26 February 2010 Accepted: 19 October 2010 Published: 19 October 2010

\section{References}

1. Fitó M, De la Torre R, Albaladejo MF, Khymenetz O, Marrugat J, Covas Ml: Bioavailability and antioxidant effects of olive oil phenolic compounds in humans: a review. Ann ist Super Sanitá 2007, 43:375-381.

2. Browning LM: $n-3$ Polyunsaturated fatty acids, inflammation and obesityrelated disease. Proceedings Nutrition Society 2003, 62:447-453.

3. Polzonetti V, Egidi D, Vita A, Vincenzetti S, Natalini P: Involvement of oleuropein in (some) digestive metabolic pathways. Food Chem 2004, 88:11-15.

4. Visioli F, Caruso D, Grande S, Bosisio F, Villa M, Galli G, Sirtori C, Galli C: Virgin olive oil Study (VOLOS): vasoprotective potential of extra virgin olive oil in mildly dyslipidemic patients. Eur J Nutr 2005, 44:121-127.
5. Covas MI, Nyyssonen K, Poulsen HE, Kaikkonen J, Zunft HJ, Kiesewetter H, EUROLIVE Study Group, et al: The effect of polyphenols in olive oil on heart disease risk factors: a randomized trial. Ann Intern Med 2006, 145:333-341.

6. Al-Azzaweie HF, Saiel M, Alhamdani S: Hypoglycemic and antioxidant effect of oeluropein in alloxan-dibetic rabbits. Life Scienc 2006, 78:1371-1377.

7. Jemai H, El Feki A, Sayadi S: Antidiabetic and antioxidant effects of hydroxytyrosol and oleuropein from olive leaves in alloxan-diabetic rats. J Agric Food Chem 2009, 57:8798-8804.

8. Miles EA, Zoubouli P, Calder PC: Differential anti-inflammatory effects of phenolic compounds from extra virgin olive oil identified in human whole blood cultures. Nutrition 2005, 21:389-394.

9. Covas Ml: Bioactive effects of olive oil phenolic compounds in humans: reduction of herat disease factors and oxidative damage. Inflammopharmacology 2008, 16:216-218.

10. Waterman E, Lockwood B: Active components and clinical applications of olive oil. Alternative Med Review 2007, 12:331-342.

11. Novelli ELB: Nutrição e Vida Saudável - estresse oxidativo e metabolismo energético. Ribeirão Preto: Tecmed 2005.

12. Novelli ELB, Santos P, Assalin H, Souza G, Rocha K, Ebaid G, Seiva F, Mani F, Fernandes $\mathrm{A}$ : $\mathrm{N}$-acetylcysteine in high sucrose induced obesity: energy expenditure. metabolic shifting for cardiac health. Pharmacol Res 2009, 59:74-79.

13. Lopaschuk GD, Folmes CDL, Stanley WC: Cardiac energy metabolism in obesity. Cir Res 2007, 101:335-347.

14. Ebaid GMX, Faine LA, Diniz YS, Rodrigues HG, Novelli ELB: Effects of digitonin on hyperglycaemia and dyslipidemia induced by high-sucrose intake. Food Chem Toxicol 2006, 44:293-299.

15. Diniz YS, Burneiko RC, Seiva FRF, Almeida FQ, Galhardi CM, Novelli Filho JLVB, Mani F, Novelli ELB: Diet compounds. glycemic index and obesity-related cardiac effects. Int J Cardiology 2008, 124:592-599.

16. Vankoningsloo S, Piens M, Lecocq C, Gilson A, De Pauw A, Renard P: Mitochondrial dysfunction induces triglyceride accumulation in 3T3-L1 cells: role of fatty acid beta-oxidation and glucose. J Lipid Res 2005, 46:1133-1149.

17. Wilson CR, Tran MK, Salazar KL, Young ME, Taegtmeyer H: Western diet, but not high fat diet causes derangements of fatty acid metabolism and contractile dysfunction in the heart of Wistar rats. Biochem J 2007, 406:457-467.

18. Jurdak N, Kanarek RB: Sucrose-induced obesity impairs novel object recognition learning in young rats. Physiol Behav 2009, 961-5.

19. Souza GA, Ebaid GX, Seiva FRF, Rocha KHR, Galhardi CM, Mani F, Novelli ELB: N-acetylcysteine na Allium plant compound improves highsucrose diet-induced obesity and related effects. eCAM Advance Acess 2008, 11:1-7.

20. Faine LA, Diniz YS, Galhardi CM, Rodrigues HG, Burneiko RC, Santana LS, Cicogna AC, Novelli ELB: Synergistic action of olive oil supplementation and dietary restriction on serum lipids and cardiac antioxidant defences. Can. J. Physiol. Pharmacol 2004, 82(11):969-975.

21. Faine LA, Rodrigues HG, Galhardi CM, Ebaid GMX, Diniz YS, Padovani CR, Novelli ELB: Effects of olive oil and its minor constituents on serum lipids. oxidative stress. and energy metabolism in cardiac muscle. Can J Physiol Pharmacol 2006, 84:239-245.

22. Gómez-Alonso S, Salvador MD, Fregapane G: Phenolic compounds profile of cornicabra virgin olive oil. J Agric Food Chem 2002, 50:6812-6817.

23. Montedoro GF, Servili M, Baldioli M, Miniati E: Simple and hydrolyzable phenolic compounds in virgin olive oil: Their extraction. separation. and quantitative and semiquantitative evaluation by HPLC. J Agric Food Chem 1992, 40:1571-8.

24. Chetty KN, Conway R, Harris KC, Hill D, Chetty S, Jain S: Dietary supplementation with olive oil influences iron concentrations in rats. Nutr Res 1999, 19:1665-1670.

25. McCue P, Zheng Z, Pinkham JL, Shetty K: A model for enhanced pea seedling vigor following low $\mathrm{pH}$ and salicylic acid treatments. Process Biochem 2000, 35:603-613.

26. Horii A, McCue P, Shetty K: Enhancement of seed vigour following insecticide and phenolic elicitor treatment. Bioresearch Technology 2006, 98:623-32.

27. Labayen I, Forga L, Martinez JA: Nutrient oxidation and metabolic rate as affected by meals containing different proportions of carbohydrate and fat. in healthy young women. Eur J Nutr 1999, 38:158-66. 
28. Lowry OH, Rosembrough NL, Farr AL: Protein measurement with the folinphenol reagent. J Biol Chem 1951, 193:265-275.

29. Jiang $Z Y$, Woollard AC, Wolf S: Lipid hydroperoxide measurement by oxidation of $\mathrm{Fe} 2+$ in the presence of xylenol orange. Comparison with TBA assay and on iodometric method. Lipids 1991, 26:853-56.

30. Nakamura W, Hojoda S, Hayashi K: Purification and properties of rat liver glutathione peroxidase. Biochem Biophys Acta 1974, 358:251-261.

31. Aebi H: Methods of enzymatic analysis.Edited by: Verloy Chemia Weinheim. (New York):Bergmeyer H. Vi , 2 1974:1-4

32. Ewing JF, Janero Dr: Microplate superoxide dismutase assay employing a nonenzymatic superoxide generation. Anal Chem 1995, 232:243-248.

33. Bass A, Brdicka PE, Eyer P, Hofer S, Pette D: Metabolic differentiation of distinct muscle types at the level of enzymatic organization. Eur J Biochem 1969, 10:198-206.

34. Novelli ELB, Souza GA, Ebaid GMX, Rocha KKHR, Seiva FRF, Mani F, Campos KE, Sforcin JM: Energy expenditure and oxygen consumption as novel biomarkers of obesity-induced cardiac disease in rats. Obesity 2010 18:1-8.

35. Buscemi S, Di Magio O, Blunda G, Maneri R, Verga S, Bompiani GD: A low resting metabolic rate is associated to body weight gain in adult Caucasian subjects: preliminary results of a 8-10 year longitudinal study. Int J Obesity 1998, 22(Suppl 1):S75.

36. Weyer C, Pratley RE, Salbe AD, Bogardua C, Ravussin E, Tataranni PA: Energy expenditure. fat oxidation. and body weight regulation: $\mathrm{A}$ metabolic adaptation to long-term weight change. J Cin Endocrinol Metab 2000, 85:1087-1094.

37. Rocha KKHR, Souza GA, Ebaid GMX, Seiva FRF, Cataneo AC: Novelli ELB. Resveratrol toxicity: effects on risk factors for atherosclerosis and hepatic oxidative stress in standard and high-fat diets. Food Chem Toxicol 2009, 47:1362-1367.

38. Rivabene R, Napolitano M, Cantafora A, Bravo E: Redox-dependent modulation of lipid synthesis induced by oleic acid in the human intestinal epithelial cell line caco-2. Exp. Biol. Med 2001, 226(1):191-198.

39. Wahle KW, Caruso D, Ochoa JJ, Quiles JL: Olive oil modulation of cell signaling in disease prevention. Lipids 2004, 39:1223-1231.

40. Hou X, Xu S, Maitland KA, Sato K, Jiang B, Ido Y, Lan F, Wals K, Wierzbicki M, Verbeuren TJ, Cohen RA, Zang M: SIRT1 Regulates hepatocyte lipid metabolism through activating AMP-activated protein kinase. J Biol Chem 2009, 283:20015-26.

41. Lewin TM, Coleman RA: Regulation of myocardial triacylglycerol synthesis and metabolism. Biochim Biophys Acta 2003, 1634:63-75.

42. Wilson-Fritch L, Nicoloro S, Choulnard M, Lazar MA, Chui PC, Reszyk J: Mitochondrial remodelling in adipose tissue associated with obesity and treatment with rosiglitazone. J Clin Invest 2004, 114:1281-89.

43. Mallet RT, Sun J, Knott EM, Sharma AB, Yurvati AHO: Metabolic cardioprotection by pyruvate: recent progress. Exp Biol Med 2005, 230:435-43.

44. Pari L, Velmurugan K: Protective and antioxidant role of caffeic acid against chloramphenicol induced hepatotoxicity in rats. Ad Phytother Res 2009, 37:79-89.

doi:10.1186/1475-2891-9-46

Cite this article as: Ebaid et al.: Effects of olive oil and its minor phenolic constituents on obesity-induced cardiac metabolic changes. Nutrition Journal 2010 9:46.

\section{Submit your next manuscript to BioMed Central and take full advantage of:}

- Convenient online submission

- Thorough peer review

- No space constraints or color figure charges

- Immediate publication on acceptance

- Inclusion in PubMed, CAS, Scopus and Google Scholar

- Research which is freely available for redistribution

Submit your manuscript at www.biomedcentral.com/submit
Biomed Central 